\title{
2006 베트남 원조공여국 회의 결과
}

표제 회의가 2006.12.14-15간 주재국 정부 및 세계은행(WB) 주관하에 30 개국, 16 개 국제기구 및 $\mathrm{NGO}$ 대표 등 300 여명이 참석한 가운데 베트 남 하노이 컨벤션 센터에서 개최된 바, 동 주요 내 용 아래 보고함.

\section{I. 핵심 요지}

\section{1. 주요 결과}

- 금번회의시 베측에서는 원조공여국 역사상 최초로 총리가 참석하였으며 기획투자부 (MPI)장관등 5 개부처 장관 및 관련기관 차 관등이 참석 - 발표를 통해 베트남으로서는 금년도에 '06-' 10 사회·경제 개발계획 (SEDP)상 2006년도 주요 목표치를 달성하 였다고(경제성장률 $8.1 \%$ 등)하면서 $\mathrm{APEC}$ 의
성공적 개최 및 $\mathrm{WTO}$ 가입등의 성과가 있었 다고 강조함

- 또한, 금년도에는 기업법·투자법·환경 보호법· $\mathrm{ODA}$ 의 효율적 활용 관련 법령 등 각종 규정이 제정 · 발효되는 등 경제 · 사회 · 환경 - 사법분야에서의 개혁 노력을 설명함.

- 특히 베측은 $\mathrm{ODA}$ 의 효율적 활용 및 운용 을 위해 Decree 131가 제정( '06.12.7발효) 되었다고 하면서 ODA 사업의 조속한 추 진을 위한 권한이양(Decentralization), 절차간소화, 타 법률과의 일관성 제고, 모 니 터 링 및 평 가 (Monitoring \& Evaluation) 강화 등의 획기적 변화를 추 구하고 있음을 강조함.

- 공여국들은 금번 회의를 통해 2005-06년간 베트남 정부가 제반 분야에서의 법률 정비 
를 통한 각종 개혁 노력을 평가하면서 경제 성장률(8.1\%) 및 빈곤률(19\%)감소 등 금년도 목표치를 대부분 달성하였음을 평가함.

- 또한 각국은 베트남 정부가 금년도 APEC 의 성공적 개최 및 150 번째 WTO 가입국 이 되었음을 축하하고 이를 통해 베트남의 향후 도약을 기대한다고 표명

- 한편, 각국은 베트남이 경제의 양적 성장 및 빈곤퇴치뿐만 아니라 성장의 질도 아울 러 고려해야할 시점이 되었음을 지적하고, 2006-2010 사회경제 개발계획(SEDP)상 의 사회통합, 환경보호, 거버넌스 개선에 주력해야 할 것임을 권고

- 2007년도 공역국들의 대 베트남 지원서약 (pledge) 총액은 44.5억불로 전년 대비(37.5 억불) $18.7 \%$ (약 7 억불)증가함.

- 일본(8.9억불), 프랑스(3.7억불), 한국(1.1 억불) 및 $\mathrm{ADB}$ (11.4억불), $\mathrm{WB}$ (세계은행, 8.9 억불) 등 서약(상세내역 별첨 참조)

\section{2. 관찰 및 평가}

- 금년도에는 지난 6 월 중간연도 원조공여국 회의시 부총리겸 외교장관이 최초 참석한데 이어 금번회의시에는 총리가 원조공여국회 의 역사상 최초로 참석한 바, 이는 베트남의 사회 - 경제발전에 있어 $\mathrm{ODA}$ 에 대한 매우 높아진 관심도를 반영한 것으로 볼 수 있음.
- 주재국은 당초 계획했던 회의일자(12.1314)를 변경하면서까지 총리의 참석을 추진

- 또한 금년도는 지난 4 월 제 10 차 전당대회시 승인한 2006-2010 사회 · 경제개발계획의 첫해로서 경제성장률 및 빈곤감소율 등 각 종 목표치가 달성되었으며

- 대내적으로는 제반분야에서의 개혁 노력 을 통한 각종 규정의 정비 등 사회 · 경제 발전을 위한 제도적 기반이 구축되었으며 - 대외적으로는 $\mathrm{APEC}$ 의 성공적 개최 및 WTO 가입을 통한 지역적·국제적 통합 에 진일보한 바,

- 금년도는 베트남의 도이모이(개혁 · 개방) 정책도입 20 주년을 맞이하여 가히 베트남 의 해(Year of Vietnam)라고 불리울 정도 로 많은 성과가 있었다고 평가됨.

- 이에 원조공여국들은 총 44.5 억불의 지원 서약을 하여 베트남 원조공여국회의 역사상 최고치를 기록한 바, 이는 원조공여국들이 베측의 개혁 노력에 대한 평가와 향후 베트 남의 경제성장에 대한 신뢰를 반영한 것으 로 볼 수 있으며 또한 동 서약액은 주재국의 기대에도 부응한 것으로 사료됨.

* 주재국 Khiem 부총리겸 외교부장관은 지 난 12.13 개최된 비즈니스 포럼시 향후 5 년 간 사회 · 경제개발을 위해 약 1,400 억불이 필요한 바, 이중 $1 / 3$ (5년간 약470억불)을 
외부로부터 유치할 것이라고 하면서 원조 공여국들 및 해외투자자들에 대한 기대감 을 표명하였음.

- 금번 원조공여국들의 서약과 관련하여 우 리나라는 양자 차원에서 일본·프랑스에 이어 제 3 위의 원조공여국이 되었으며(작 년도 4위)

- 중국의 서약불참(작년도 2 억서약, 3 위) 및 $\mathrm{ADB}$ 의 서약액 증가(작년도 5.4 억불에서 금년도 11.4 억불)가 주목되는 바

- 우리로서는 동 배경 등을 파악하여 우리의 대베트남 $\mathrm{ODA}$ 계획수립에 참고할 필요가 있음. (가능시 $\mathrm{ADB}$ 와의 $\mathrm{co}$-financing 사 업 추진도 고려)

- 한편, 주재국 정부가 금년도에 각종 규정을 많이 정비하였으나 이를 효과적으로 이행하 기 위해서는 규정과 절차에 대한 관계기관 의 이해와 전문성등이 제고될 필요가 있는 바, 향후 주재국 정부의 각 규정의 이행 지침 작성 과정시 원조공여국들과의 충분한 협의 를 거쳐 사업 수행상의 애로사항들이 많이 반영되어야 할 것으로 사료됨. (동 과정에서 의 우리측 적극 참여 필요)

- 특히 일부 공여국들은 새로 제정된 ODA 활용에 대한 Decree 131의 기본방향은 바람직하나, 지방정부 · 일선 행정기관 등 실제 $\mathrm{ODA}$ 사업현장에서 적용되기에는 많은 부분이 보완되어야 함을 지적하고
있으므로,

- 우리는「중부지역 병원건립사업」등 대규 모 사업을 앞두고 있으므로 동 법률 시행 으로 인한 정책변화 및 개별 사업에의 파 급효과에 대한 면밀한 검토가 필요한 것 으로 보임.

\section{II . 의제별 세부 논의내용}

\section{1. 개회식}

- 개회식에는 주재국의 Nguyen Tan Dung 총리, Vo Hong Phuc 기획투자부 장관을 비 롯한 5 개부처 장관, Klaus Rohland Worldbank 베트남 Country Director 등이 참석함.

- 폐회식에는 Pham Gia Khiem 부총리겸 외교장관이 참석

- Nguyen Tan Dung 총리는 개막연설을 통 해 베트남은 올해 WTO에 가입하였고, $8.1 \%$ 의 경제성장률을 기록하여 당초 목표했던 $7.5 \%$ 를 초과 달성하였으며, 2005년 22\%에 이르던 빈곤율을 $19 \%$ 까지 감소시키는 등 많 은 성과를 이루었음을 설명하고, 이는 도이 모이 이후 지속적으로 추진해온 개혁의 결 과라고 평가함.

- 또한 $2006^{\sim} 2010 \mathrm{SEDP}$ 가 마무리되는 
2010년도에는 1인당 GDP 1,100USD를 달성하고 2020년도에는 명실상부한 「공 업 국가」(Industrialized Country)로 발돋 움한다는 경제개발 목표를 소개

- 다만 이러한 목표를 달성하기 위해서는 부 패 척결, 지속가능한 성장기반 조성 등의 과제가 선행되어야 하는바 이에 대한 국제 사회의 조언 및 지지를 당부

\section{2. 경제 성장과 기업환경}

\section{가. 베측 설명요지}

- 베측은 1차 사회경제개발계획(2001 2005) 의 결과 베트남 경제가 동기간중 연평균 $7.5 \%$ 의 GDP 성장 및 750 만명의 고용창출 등의 양적 확대를 이루었으나 공기업민영 화, 빈곤계층 감소 등 경제의 질적성장은 상 대적으로 미흡하였다고 자체 평가하였음.

- 2차 사회경제개발계획 이행을 통해 2006 2010년간 1인당 GDP 1,100불 달성, 빈곤인구 $10 \%$ 감소, 도시지역 청정수 공급 률 확대(95\%) 등 경제 및 사회의 질적 수준 향상을 추구할 계획임을 소개함.

- 또한 재무부, 교통부, 교육부 장관 등이 참 석, 금융-은행 - 공기업 등 분야별 개혁 계획 및 베트남의 인적자원 개발 계획을
발표함.

\section{나. 주요 토의 내용}

- 대다수 공여국 및 국제기구 대표들은 지난 5 년간 베트남의 경제적 성과는 베트남 정부 및 민간의 개혁노력의 결과라고 평가하고, 향후 지속적인 경제 성장을 위해서는 반부 패 척결 등 행정개혁 및 시장경제의 확립이 필요함을 강조하고 지방정부의 행정능력 배 양, 사법부 독립, 소수자 보호, HIV/AIDS 대책 등 지속 가능한 발전을 위한 과제를 제시함.

- 또한 2006년 베트남의 WTO 가입, $\mathrm{APEC}$ 정상회의 개최, $\mathrm{UN}$ 안정보장 이사회 가입 등은 베트남의 국제적 위상을 높이는 계기 가 된 것으로 평가하고

- 특히 WTO 가입은 베트남 경제에 큰 기회 와 함께 시장 경제 확립이라는 과제를 주 고 있는바 $\mathrm{WTO}$ 가입의 효과를 극대화하 기 위하여 가입 조건을 이행하기 위한 정 부의 노력에 민간 부분이 적극적으로 참여 하여 가입조건 이행이 실질적인 투자환경 개선으로 이어질 수 있도록 해야 한다고 조언함.

- 우리 대표는 발언을 통해 수출주도형 경제 성장을 해온 우리나라의 경험이 베트남의 
경제 개발과정에서 유용한 본보기가 될 것

이라고 전제하고

- 수출주도형 경제성장을 위해서는 적절한 수출신용의 공급이 필수적인바 한국은 2005년 지식공유사업을 통해 베트남 개발 은행의 설립에 기여한 바 있음을 소개하고 향후 동 은행을 통행 베트남내 수출신용제 도의 적극적인 도입과 확산이 이루어지기 를 기대한다고 언급함.

\section{3. 사회 발전과 지속가능한 환경}

\section{가. 베측 설명요지}

- 베측은 경제의 양적 성장과 더불어 사회적 통합이 베트남의 지속적인 발전을 위해 중 요한 과제임을 인식하고, HIV/AIDS 확산방 지, 사회 안전망 구축, 자연자원 관리 및 환 경 보호 등을 위한 베정부의 노력을 소개하 는 한편, 이들 분야에 대한 국제사회의 지속 적인 지원을 요청하였음.

- 특히, 베측은 이들 사회적 과제 수행을 위 해 HIV/AIDS 예방 및 관리를 위한 법률 제정, 사회보험제도 도입 등 법적 · 제도적 기반 구축이 진행중임을 강조하고, 중장기 적으로 가시적인 성과를 도출할 수 있을 것으로 언급

- 아울러, 2005년 11월이후 국내에서 새로운
조류 인플루엔자 발병사례가 없었음을 강조 하고, 조류 인플루엔자 예방을 위해 UN, $\mathrm{WB}, \mathrm{EU}$ 및 베측 전문가가 참여하는 National Work Plan이 진행중임을 소개함.

\section{나. 주요 토의내용}

- 대다수의 공여국들은 경제의 양적 성장과 함께 성장의 질 및 사회적 통합이 중요하다 는데 인식을 같이하고 성장과정에서 소외될 수 있는 사회적 소수자에 대한 배려가 필요 한 시점임을 강조함.

- 특히 캐나다, 뉴질랜드, 스위스, 노르웨이 대표는 빈곤층이 많은 산간지역 및 소수민 족(Ethnic minority)에 대한 베측의 관심 을 촉구하였고, 소수민족 전통문화의 보존 은 사회의 활력 유지를 위해 중요함을 언급

- 아울러 UN Resident Coordinator는 투명 하고 민주적이며 신뢰할 수 있는 공공행정 과 환경 및 자연자원에 대한 지속적인 관리 가 향후 $\mathrm{ODA}$ 사업이 나아갈 방향을 결정하 게 될 것임을 언급함.

- 아시아 개발은행(ADB)은 건강한 노동력의 확보는 경제발전의 필수요소이므로, 향후 HIV/AIDS 확산방지를 위한 프로젝트를 지 원할 방침임을 소개하고, 조류 인플루엔자 예방을 위한 지역 차원의 협력을 강조함. 
- 우리 대표는 지난 6 월 중간연도 원조공여국 회의시 $\mathrm{SEDP}$ 의 세 축(three pillars)중 하나 인 환경분야에 대한 2006-2010간 투자비중 이 작다고 지적한 점을 상기시키면서 이후 베측 정부가 환경분야에 대한 투자증대 및 환경기금 설립 등 재원의 다양화를 위한 노 력을 경주하고 있음을 평가함.

- 또한, 베측은 환경보호측면만 중시할 것 이 아니라 환경산업의 증진에 대해서도 역점을 두어 이를 통한 지속가능한 개발 을 이룩해야 할 것이라고 언급하고 이를 위해 각국과의 환경기술에 대한 지원논의 가 보다 활성화되어야 할 것이라고 강조 - 한편, 우리 대표는 지난 11월 한국에서 조 류 인플루엔자가 발생한 것과 관련하여, 우리나라가 베측에 동건 관련 설명을 직 접하는 등 양국간 긴밀히 협조를 하고 있 다면서 향후 동건 발생관련 베측을 비롯 한 관련국가와 상세한 정보교환을 통해 적절한 조치를 취해나갈 예정임을 설명

\section{4. 법적 · 제도적 기반 구축}

\section{가. 베측 설명요지}

- 베측은 부패사범에 대한 엄정한 처벌, 반부 패법 시행에 대한 모니터링 강화 등 부패와 의 전쟁을 추진함으로써 그간 공여국들이 민간차원의 경제활동 및 $\mathrm{ODA}$ 의 효과적 집
행의 주요한 저해요인으로 지적해 온 부패 에 대해 단호히 대처해 나갈 것임을 언급함.

- 아울러 사법제도를 개혁하고 2006-2010년 간 2단계 공공행정 개혁 프로그램을 추진함 으로써 행정의 효율성을 제고하고, 부패의 근본 원인을 제거해 나갈 것임을 밝힘.

\section{나. 주요 토의내용}

- 대다수 공여국들은 부패 척결을 위한 베정 부의 의지에 대해 높이 평가하고, 지방정부 의 지나친 관료주의(red tape), 상-하위 기 관간 서로 다른 법률 해석, 공무원의 낮은 전 문성 등도 시급히 해결해야 할 과제임을 지 적함.

- 아울러, 캐나다, 미국, 스웨덴, 네덜란드 등 은 향후 베트남의 성패는 법치주의(rule of law)에 있음을 강조하고, 인권 보호, 시민사 회의 참여 보장 등을 위해 사법개혁이 필수 적이며, 이를 위한 베측의 노력에 대해서는 향후 적극 지원할 것임을 약속하였음.

\section{5.국제적 - 지역적 통합}

\section{가. 베측 설명요지}

- 베측은 지난 11 월 11 년에 걸친 협상끝에 150 
번째 WTO 가입국이 되었음을 소개하고, WTO 가입 공약을 충실히 수행할 것이며, 이를 위해 WTO 가입공약 이행을 위한 기술 적 원조 프로그램을 영국과 호주의 지원하 에 추진할 예정임을 언급함.

- 아울러 지난 11.12-19 하노이에서 개최된 $\mathrm{APEC}$ 을 통해 투자 및 무역 자유화 촉진을 위한 많은 진전이 있었다고 평가하고, 이번 $\mathrm{APEC}$ 은 회원국간 경제적 기술적 협력강화, 중소기업 경쟁력 강화를 위한 각국의 노력 약속 등 많은 성과를 거둔 성공적인 행사였 다고 소개함.

\section{나. 주요 토의내용}

- 참가자들은 베트남의 WTO 가입 및 성공적 인 APEC 개최를 축하하는 한편, 이번 WTO 가입은 베트남에게 새로운 기회인 동시에 또다른 도전이 될 것이라고 평가함.

- IMF를 비롯 많은 참가자들은 WTO 가입으 로 인한 실질적 혜택을 누리기 위해서는 거 시경제 조정능력 강화, 그간 보호무역의 특 혜를 누리던 산업영역의 경쟁력 제고, 금융 시스템 개선, 공기업 민영화 등이 필요함을 언급하고, $\mathrm{WTO}$ 기준에 부합하는 기업환경 개선에 최선을 다해줄 것을 촉구함.
- 아울러 국제 $\mathrm{NGO}$ 는 $\mathrm{WTO}$ 가입으로 인해 일부 빈곤층의 생활수준이 악화될 수도 있 음을 지적하고 WTO 가입공약 이행에 있어 서 베정부의 유연성이 필요함을 언급함.

- 우리측은 2006년도에 베트남의 WTO가입 및 $\mathrm{APEC}$ 의 성공적 개최를 축하하면서 베트 남의 WTO 가입관련 협상 초기부터 우리나 라가 적극 개입, 지지하였음을 강조함.

- 또한 우리나라는 작년도 $\mathrm{APEC}$ 의장국으 로서 부산 $\mathrm{APEC}$ 개최이후 $\mathrm{SOM}$ 의장실 및 준비기획단의 방베를 통해 경험을 전수 하였으며 또한 경호 측면에서의 물적지원 과 합동교육 등을 실시하여 2006 하노이 $\mathrm{APEC}$ 의 성공적 개최를 위해 많은 노력을 경주하였다고 언급함.

-한편, 금년도 $\mathrm{APEC}$ 개최시 작년도 Busan Roadmap의 이행을 위한 Hanoi Action Plan의 채택과 관련하여 베측과 긴밀히 협의하였으며 금번 회의시 주요 성 과물중의 하나인 Stand-Alone Statement on WTO DDA의 채택을 주도 하였다고 설명

- 한편, $\mathrm{APEC}$ 계기 한 · 베 정상회담시 우 리나라 무상원조 역사상 최대규모(3,500 만불)인 베트남 중부지역 병원건립사업에 대한 시행약정이 체결되었다고 설명하면 서 동 사업의 성공적 수행을 위한 베측의 협조를 당부 


\section{6. 원조의 조화, 집행, 효율성 제고}

\section{가. 베측 설명요지}

- 베측은 국제사회에서 신뢰할 수 있는 파트 너가 되기 위해 $\mathrm{ODA}$ 동원, 관리, 활용 과정 의 투명성을 높이고 원조효과를 제고하기 위한 다양한 노력을 기울여 오고 있으며, 이 에 따라 공여국들의 ODA 지원공약대비 집 행비율도 개선되고 있음을 소개함.

- 정책 측면에서 MPI는 사회경제개발5개년 계획(2006-2010)의 이행을 실현할 ODA 재원동원의 기초가 될 「2006-2010 ODA 전략프레임워크」를 작성하여 총리실에 승 인을 받기 위해 제출

- 법률·제도 측면에서는 Decree 131을 발 표하여 $\mathrm{ODA}$ 관리 및 활용 관련 사업의 집 행 가속화를 위한 권한의 이양, 절차간소 화 및 원조조화, 타 법률과의 일관성 제고, 모니터링 및 평가 강화 등의 획기적 변화 를 도모

- 특정 보고서 형식 및 체계, 조달절차 등에 서 공여국(기관)과의 조화를 달성하고, 웹 사이트(http://dad.mpi.gov.vn)를 통해 50 개국 이상의 공여국간 개발원조데이터 베이스( $\mathrm{DAD})$ 를 공유하는 등 원조조화를 위한 지속적 활동 수행 및 그에 따른 성과 를 거양

- 지난 3년간 공여국, 국제 NGO, 베트남 정
부기간이 폭넓게 참여한 원조효과 관련 파 트너쉽 그룹(PGAE)의 활동을 통해 베트 남에서의 ODA 효과제고를 위한 노력을 기울였으며, Hanoi Core Statement를 채택하고 이행함으로써 베트남을 원조효 과에 관한 파리선언을 가장 모범적으로 이 행한 국가로 만듬

- 그러나 상기 성과에도 불구하고 2006년도 에는 다음과 같은 제약과 어려움이 있었음.

- $\mathrm{ODA}$ 관리 및 활용과 직간접적으로 관계 있는 법률간 일관성 미흡

- line ministrys와 정부의 오너쉽 부족으로 질 낮은 사업계획서 작성

- 부적절한 원조제공방식의 선정으로 인한 자국내 재원조달 어려움 등 사업 준비 및 승인 지연

- 부지정리, 토지보상, 재정착 추진과정에서 의 문제점 발생 등

- 2006년도의 ODA 동원 및 활용 평가결과를 기초로 2007 년도에는 다음 조치내용을 중 점적으로 이행 예정임.

- Decree 131과 관련한 사업추진반(PMU) 의 운영 등을 포함한 구체이행지침 마련, 2006-2010 ODA 전략프레임워크의 이행 을 위한 행동계획과 하노이핵심성명의 이 행계획 수립

- 모든 수준에서 효과적인 보고, 모니터링, 
평가시스템 수립

- 공여국과의 긴밀한 협력을 통해 원조절차

의 조화과정을 가속화

- 모든 수준에서의 ODA 관리 및 이행 관련 역량강화를 위한 훈련 등

\section{나. 주요 토의내용}

- 대다수의 공여국 및 국제 $\mathrm{NGO}$ 들은 베트남 정부의 강력한 리더쉽과 모범적인 수원태세 를 높이 평가하고, 특히 원조효과 관련 파리 선 언 을 현 지 화 한 Hanoi Core Statement(HCS)의 구체적이고 적극적인 이행노력과 금번 Decree 131 제정을 크게 환영함.

- 한편, Decree 131 의 성공적인 이행 및 원조 사업의 집행을 가속화하기 위해서는 line ministrys와 지방(성) 정부 및 집행기관의 능력강화가 필요하며, 사업승인, 국제협정 체결 등의 행정절차 간소화 노력과 법률적 정비뿐만 아니라 사업관계자들의 의식변화 도 긴요함을 설명함.

- 스웨덴, 카나다, $\mathrm{EC}$, 호주 등은 원조조화의 중요성을 강조하면서, 공여국의 원조절차 및 방식을 베트남 정부의 절차와 시스템에 조화시키는 노력도 필요함을 강조하는 한 편, 원조효과 제고를 위해 거래비용 (transaction cost)의 감소 노력을 중점 추 진해야 한다는 입장도 피력함.

- $\mathrm{ADB}, \mathrm{UN}$ 등은 원조비용에 대한 기준(cost norm) 관련, 사업지연시 계획단계와 집행단 계에서의 원조비용의 차이 발생, 시장가격 과의 차이(gap)로 인한 문제점을 설명하면 서 이의 개선을 위한 노력을 촉구함.

- 한편, 일본은 2008년 JICA와 JBIC의 통합 을 통해 유·무상사업간 시너지 효과 및 원 조효과 제고 계획을 설명함.

\section{7. 각국 및 국제기구의 2007년 대 베트남 지 원약속}

- 2007년도 대 베트남 지원서약(pledge) 총액 은 44.5 억불로 전년 약속액(37.5억불) 대비 약 7 억불 증가함.

- 일본(8.9억불), 프랑스(3.7억불), 한국(1.1억 불)등이 지원을 약속하였으며 그 외 $\mathrm{ADB}(11.4$ 억불), $\mathrm{WB}$ (8.9억불), $\mathrm{UN}$ 기구(0.7 억불), $\mathrm{NGO}$ (1.8억불) 등 국제기구/단체도 지속적인 대 베트남 지원을 서약

- 우리 대표는 한국정부는 베트남 정부가 $\mathrm{SEDP}$ 와 연계하여 부패방지를 위한 행정개 혁 및 금융제도 개혁 등의 노력을 하고 있음 
을 평가하고, 2007 년에는 약 1.1 억불의 유 ·

무상원조를 지원할 계획임을 소개함.

[자료: 주베트남대사관] 